TP Periodica Polytechnica Chemical Engineering

61(1), pp. 3-9, 2017

DOI: $10.3311 /$ PPch.10185

Creative Commons Attribution (i)

RESEARCH ARTICLE

\section{Modelling and Characterization of the Sorption of Kynurenic Acid on Protein Surfaces}

\author{
Ádám Juhász ${ }^{1 *}$, Edit Csapó ${ }^{1,2}$, László Vécsei ${ }^{3}$, Imre Dékány ${ }^{1,2^{*}}$
}

Received 18 October 2016; accepted after revision 13 December 2016

\begin{abstract}
This paper presents a surface plasmon resonance (SPR) spectroscopy-based evaluation process which provides information on kinetic and thermodynamic aspects of the interactions between proteins and a drug molecule. Reversible binding of kynurenic acid (KYNA) on human (HSA) and bovine (BSA) serum albumin-modified gold sensor surface has been investigated under physiological conditions at various temperatures. The SPR sensorgrams were fitted via nonlinear parameter estimation method by using pseudo first order kinetic model. Based on the concentration dependence of the estimated observed rate constants $\left(k_{\text {obs }}\right)$ the association $\left(k_{a}\right)$ and dissociation $\left(k_{d}\right)$ constants as well as the equilibrium constants $\left(K_{A}\right)$ and the Gibbs free energy $\left(\Delta G^{0}\right)$ change were calculated at different (10-35 $\mathrm{C}^{\circ}$ ) temperatures. Furthermore, the enthalpy $\left(\Delta H^{0}\right)$, entropy $\left(\Delta S^{0}\right)$ and heat capacity changes $\left(\Delta C_{p}\right)$ of KYNA-protein complex formation were also calculated.
\end{abstract}

\section{Keywords}

surface plasmon resonance spectroscopy, kynurenic acid, serum albumins, binding kinetics, van't Hoff relation, enthalpy, entropy, heat capacity

\footnotetext{
${ }^{1}$ MTA-SZTE Supramolecular and Nanostructured Materials Research Group, University of Szeged, H-6720 Dóm tér 8., Szeged, Hungary

${ }^{2}$ Department of Medical Chemistry, Faculty of Medicine, University of Szeged, H-6720 Dóm tér 8., Szeged, Hungary

${ }^{3}$ MTA-SZTE Neuroscience Research Group, University of Szeged, Department of Neurology, H-6725 Semmelweis u. 6, Szeged, Hungary

*Corresponding authors, e-mail: juhaszadam79@gmail.com; i.dekany@chem.u-szeged.hu
}

\section{Introduction}

For protein-based controlled drug delivery and drug release systems the study of the interactions between the protein as the carrier and a drug molecule play a determinant role in pharmaceutical developments [1,2]. Detailed kinetic and thermodynamic characterization of protein-ligand interactions provide several important data on the mechanisms of the drug release process. Numerous radio-labelled and "label-free" equilibrium or time- resolved analysis techniques are available which able to monitor and quantify protein-ligand bindings. The SPR spectroscopy is one of the most useful quasi two-dimensional technique which is able to measure real-time association and dissociation processes between DNA-DNA, DNA-protein, lipid-protein and protein- or peptides-drug molecules in a label free environment $[3,4]$. While one of the interacting partners is immobilized onto the sensor surface, the other is flow in solution over the surface or exist as bound (surface complex) form. During this progression, the refractive index at the interface undergoes change, this being directly related to the amount of the biomolecules adsorbed on the surface of the biosensor chip.

In general, SPR sensors are thin-film refractometers that measure changes in the refractive index occurring at the surface of a gold (or silver) thin layer based on a surface plasmon phenomenon. A surface plasmon excited by a light wave propagates along the metal layer, and its evanescent field probes the sample (solution of analyte) in contact with the surface of the noble metal film. A change in the refractive index of the dielectric gives rise to a change in the propagation constant of the surface plasmon, which through the coupling condition alters the characteristics of the light wave coupled to the surface plasmon (e.g. coupling angle, coupling wavelength, intensity or phase). Based on the listed characteristic of the light wave SPR sensors are classified as sensors with angular, wavelength, intensity, or phase modulation [5]. Commonly used SPR arrangement is the so-called Kretschmann-configuration (Fig. 1) in which case the momentum of the incident light is coupled to the free oscillations of the conduction electrons at a metal surface through a prism in order to increase in the wavenumber of the light, thus generating the conditions of surface plasmon resonance. 
The propagation constant of the surface plasmon $\left(\mathrm{k}_{\mathrm{SP}}\right)$ at the metal-dielectric interface is expressed as

$$
k_{S P}=\frac{2 \pi}{\lambda} \sqrt{\frac{\varepsilon_{d} \varepsilon_{m}}{\varepsilon_{d}+\varepsilon_{m}}}
$$

where $\lambda$ is the wavelength in vacuum, $\varepsilon_{\mathrm{d}}$ and $\varepsilon_{\mathrm{m}}$ are the complex permittivity of dielectric and metal, respectively. The light wave cannot be coupled directly, because the real part of the surface plasmon's propagation constant $\operatorname{Re}\left(\mathrm{k}_{\mathrm{SP}}\right)$ is larger than the wavenumber of the light's wave vector that is parallel to the surface. The surface plasmon can be excited when the wavenumber of light is increased by a prism

$$
\frac{2 \pi}{\lambda} n_{p} \sin (\theta)=\operatorname{Re}\left(k_{s p}\right)
$$

where $n_{p}$ is the refractive index (larger than the refractive index of dielectric) of the prism and $\theta$ is the angle of incidence. In the case of wavelength modulation the varying the wavelength $(\lambda)$ of polychromatic light at a fixed angle $(\theta)$ the matching condition can be achieved and the surface plasmon can be excited by an evanescent wave propagating along the metal-dielectric interface. Chemical or physical adsorption onto the gold surface changes the refractive index of the dielectric, thereby the propagation constant of the surface plasmon is also changed [6].

Still, several research groups have published their results in the topic of characterization of different biomolecule interactions [7-10], but only a few articles offer deeper information on the temperature-dependent interactions between peptides or proteins and potential drug molecules by using SPR $[11,12]$.

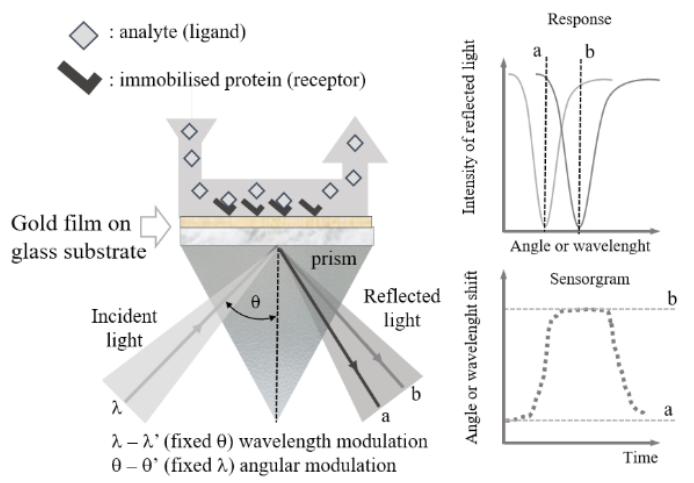

Fig. 1 Schematic diagram of a Kretschmann-arrangement SPR biosensor and its typical response diagram and sensorgram

The objective of the present work was to provide complementary data on the interactions between serum albumins and KYNA by using only SPR experiments. In recent years the field of schizophrenia investigation has led to the impression that only dopamine plays an intermediary role in the pathophysiology of the disease and that the main abnormalities lie elsewhere. In particular, deficits in brain glutamatergic systems are proposed to play a prominent role in the pathophysiology of the disease. KYNA is an endogenous glutamate antagonist with a preferential action at the glycine-site of the N-methyl-daspartate-receptor [13]. Prescott et al. have been published an interesting work about the dual action of KYNA on $\alpha$-amino3-hydroxy-5-methyl-4-isoxazolepropionic acid receptor (also known as AMPA receptor, AMPAR) responses [14].

In the course of our previous works, the SPR based characterization of the interactions between three different peptide fragments of human glutamate receptor (GluR1) and KYNA has been presented. Besides quantitation of the interactions, the enthalpy change of the binding process on certain peptide fragment-modified gold surfaces were also reported $[15,16]$. In the present work, instead of relatively small model peptide fragments, the HSA and BSA proteins were immobilized onto the sensor surface and their interactions with KYNA were investigated by SPR technique. This procedure is beneficial for comparison of the magnitude and the sign of thermodynamic parameters of the above mentioned systems. However, the serum albumins are not well-defined receptors of KYNA as AMPA, but their binding affinity could be a determinant factor in the mentioned dual action of KYNA.

To supplement the earliest results, in the present work we have functionalized the sensor surfaces with HSA and BSA and the SPR sensorgrams of the binding of KYNA on proteinmodified gold surface were registered and analyzed in order to give detailed kinetic parameters of the above mentioned protein-drug molecule interactions. Based on the temperature dependence of the kinetic parameters the equilibrium constants $\left(K_{\mathrm{A}}\right)$, Gibbs free energy- $\left(\Delta G^{0}\right)$, enthalpy- $\left(\Delta H^{0}\right)$, entropy- $\left(\Delta S^{0}\right)$ and heat capacity $\left(\Delta C_{\mathrm{p}}\right)$ changes were also calculated.

\section{Experimental Procedure \\ 2.1 Materials}

The following chemicals were used in the experiments: KYNA ( $\geq 98 \%$, Sigma), $\mathrm{NaCl}\left(\geq 98 \%\right.$, Molar), $\mathrm{NaH}_{2} \mathrm{PO}_{4}(\geq 99 \%$, Sigma-Aldrich), $\mathrm{Na}_{2} \mathrm{HPO}_{4}(\geq 98.5 \%$, Sigma) HSA ( $\geq 98.0 \%$, $\mathrm{M}_{\mathrm{w}}=66.4 \mathrm{kDa}$, Sigma), BSA ( $\geq 98.0 \%, \mathrm{M}_{\mathrm{w}} \sim 66 \mathrm{kDa}$, Sigma $)$. All the starting materials were used without further purification. In all cases the KYNA-, the protein stock solutions and the phosphate buffer (containing $150 \mathrm{mM} \mathrm{NaCl}$ ionic strength at $\mathrm{pH} 7.4$ $( \pm 0.02))$ were freshly prepared using Milli-Q ultrapure water $\left(18.2 \mathrm{M} \Omega \mathrm{cm}\right.$ at $\left.25^{\circ} \mathrm{C}\right)$

\subsection{SPR spectroscopy}

During the SPR spectroscopy investigations a temperaturecontrolled, two-channel instrument innovated by the Institute of Photonics and Electronics (Prague, Czech Republic) was applied. The measuring platform contains two sensing channel with two separated flow chamber, each chamber volume is 0.5 microliter. The container of the gold-coated SPR chip is 
a microscope glass compatible device with $20 \times 26 \mathrm{~mm}$ dimensions. The SPR chip intrinsically is a $50 \mathrm{~nm}$ thick gold layer on a glass substrate. The flow system is a classic microfluidic flow system which connects to the sensor surface with the buffer solution tanks. The sample-containing buffer is moved by a peristaltic pump over the sensor surface through the flow channels. In the case of our wavelength-modulated apparatus, the resonance conditions are created by a fixed incident angle while the wavelength of the light source is changed. The light source is an Ocean Optics HL-2000 type tungsten halogen source with $6.8 \mathrm{~mW}$ output power (output power coupled into a $600 \mu \mathrm{m}$ UV/VIS fiber and measured with an optical power meter integrated from 200-1100 nm) and 360-2400 nm wavelength range. Reflected light intensity is monitored in $574-1000 \mathrm{~nm}$ spectrum range using IPE AS CR S2010 spectrometer. The spectrometer communicates with a PC via USB connection and data registration is carried out by SPR UP software.

During SPR measurements the flow rate of $50 \mu \mathrm{L} \mathrm{min}^{-1}$ was used at constant temperature, holding physiological condition (150 $\mathrm{mM} \mathrm{NaCl}$ in phosphate buffer solution at $\mathrm{pH}=7.40$ ). Serum albumins were immobilized on the gold surface at room temperature from aqueous solution $\left(\mathrm{c}_{\text {protein }}=50.0 \mu \mathrm{M} ; 33.0 \mathrm{mg}\right.$ BSA and $33.2 \mathrm{mg}$ HSA in $10 \mathrm{ml}$ buffer) via an Au-S covalent bond. On the second case, the reversible binding of KYNA on a protein-functionalized chip was studied in the temperature range between 283.15 and $303.15 \mathrm{~K}$. Sensorgrams were recorded with SPR UP 1.1.11.3 (2014 IPE AS CR) control software, while the evaluation of extracted data was carried out in Microsoft Excel program.

\subsection{Immobilization of serum albumins}

In order to study the interaction between KYNA and serum albumins by SPR spectroscopy firstly the proteins were immobilized onto the surface of gold-coated SPR chip from aqueous solutions. The registered SPR sensorgram of BSA has been presented previously [17] therefore the Fig. 2 represents only the preparation of HSA-functionalized gold sensor surface.

As it can be seen the adsorption of HSA, similar to BSA, are not fully reversible, substantial part of the adsorbed amount remains irreversibly bound at gold surface. Most probably the protein was covalently attached via cysteine residue. The immobilization process was repeated twice until even measurable adsorption detected.

According to the calculated parameters of HSA adsorption, most probable a monomolecular protein layer was prepared on the gold surface. It was found that the monolayer amount of HSA is $\mathrm{m}^{\mathrm{s}}=63 \mathrm{ng} / \mathrm{cm}^{2}$ and the cross-sectional area is $\mathrm{a}_{\mathrm{m}}=175 \mathrm{~nm}^{2}$. These values show a good agreement with the suggested size of a human serum albumin protein in solution [18]. Under same conditions for BSA $\mathrm{a}_{\mathrm{m}}=128.4 \mathrm{~nm}^{2}$ was determined [12].

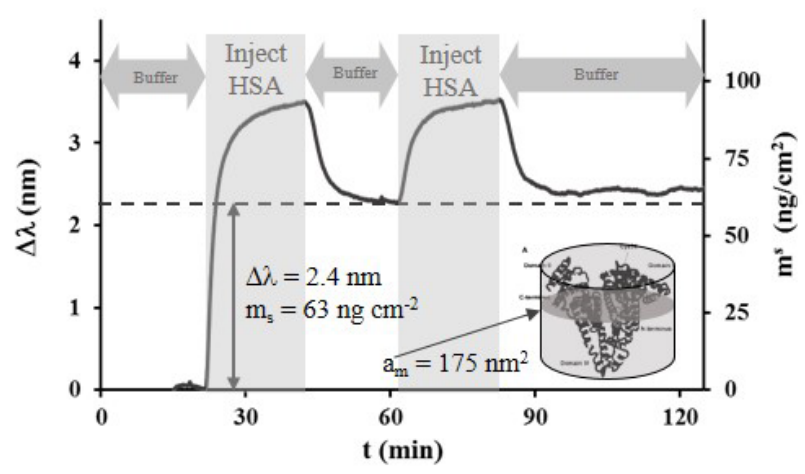

Fig. 2 Sensorgram of immobilization of HSA on gold sensor surface from aqueous $\left(\mathrm{c}_{\mathrm{HSA}}=50 \mathrm{mM}\right)$ solution $\left(\mathrm{T}=298.15 \mathrm{~K} ; \mathrm{Q}=50 \mu \mathrm{L} \mathrm{min}{ }^{-1}\right)$

\subsection{Binding of KYNA to serum albumins}

Temperature-dependent SPR measurements were carried out to determine kinetic and thermodynamic parameters of KYNAserum albumin interaction. During the examinations a flow rate of $50 \mu \mathrm{l} \mathrm{min}^{-1}$ was applied at different temperature (283.15, $288.15,293.15,298.15 \mathrm{~K}$ in the case of KYNA-BSA and $288.15,293.15,298.15,303.15 \mathrm{~K}$ in the case of KYNA-HSA) in the concentration range of $1.0-10.0 \mathrm{mM}$. The binding interaction, namely the association and dissociation of drug molecule and protein composed surface complex was studied in PBS solution at $\mathrm{pH}=7.4$ under physiological conditions $(150 \mathrm{mM}$ $\mathrm{NaCl})$. After the immobilization of appropriate protein KYNA solutions $(\mathrm{c}=1.0,1.5,2.0,3.0,4.0,5.0,7.0,10.0 \mathrm{mM})$ were injected and the sorption process $(\sim 10 \mathrm{~min})$ was followed by rinsing with buffer. The SPR sensorgrams were analysed in real time by SPR UP software package that permits of determination of the resonant wavelength in both sensing channels.

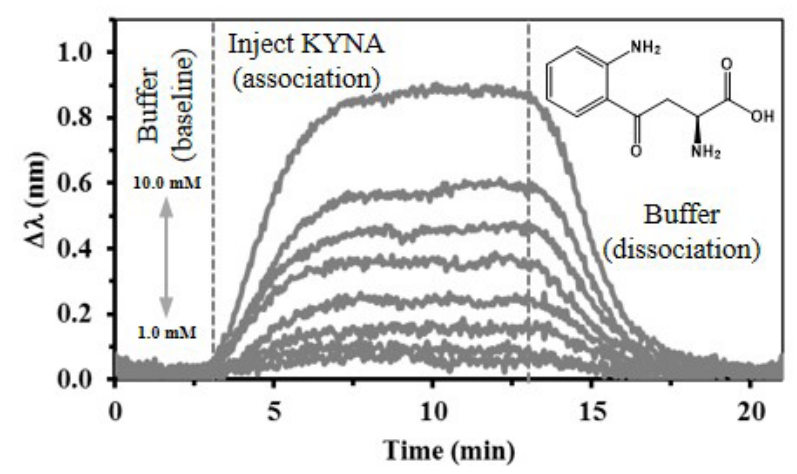

Fig. 3 Representative sensorgrams of the interaction of KYNA with BSA immobilized on gold surface at $283.15 \mathrm{~K}$.

As presented in Fig. 3 while the solved ligands bind to the immobilized protein, during an association phase the binding sites become occupied and the positive slope of SPR curve can be registered. Reducing of the number of binding sites the positive slop bend down and sensorgrams reach a saturated "steady-state" phase. This achieved stationary wavelength shift $(\Delta \lambda)$ value corresponds to the final steady-state surface amount of bound form. This analyte concentration dependent 
wavelength shift relates to the concentrations of surface complex and after adequate calibration can be used to determine the binding affinity constant $\left(\mathrm{K}_{\mathrm{D}}\right)$. Under the dissociation phase the ligands were removed from the binding sites via continuous flow of washing buffer solution.

\section{Results and Discussion}

\subsection{Determination of rate constants}

Based on the sensorgrams which describe the association and dissociation of the surface complex, the $k_{\mathrm{a}}$ and $k_{\mathrm{d}}$ and the corresponding $K_{\mathrm{A}}$ were determined at appropriate temperatures according to the following evaluation process. For calculations of the kinetics parameters the $\mathrm{A}+\mathrm{B} \leftrightarrow \mathrm{AB}$ type bimolecular reaction model was used, where A corresponds to the drug molecule, $\mathrm{B}$ is the protein, while AB is the KYNA-serum albumin complex. Assuming that the association of drug molecule-protein complex is first order in reactants and the dissociation is first order in intermediate complex provides following overall rate law.

$$
\frac{d[A B]}{d t}=k_{a}[A][B]-k_{d}[A B]
$$

Taking into account the specification of the applied SPR technique, the concentration of KYNA solution is held constant $\left([\mathrm{A}]_{0}=[\mathrm{A}]\right)$, and the total concentration of the surface-bound peptide equal the sum of the free and intermediate complex form $\left([\mathrm{B}]_{0}=[\mathrm{B}]+[\mathrm{AB}]\right)$. In this way, concentration of KYNA can be replaced with the concentration of KYNA stock solution while the concentration of SA-KYNA complex is replaceable with the difference of total surface concentration of bound polypeptide and free form of polypeptide $\left([\mathrm{AB}]=[\mathrm{B}]_{0}-[\mathrm{B}]\right)$. Based on the above mentioned considerations the rearranged rate law can be written as.

$$
\frac{d[A B]}{d t}=\left(k_{a}[A]+k_{d}\right)[B]-k_{d}[B]_{0}
$$

Additionally, when the formation of intermediate complex is favourable $\left(\mathrm{k}_{\mathrm{a}}>>\mathrm{k}_{\mathrm{d}}\right)$ the last term of equation (4) is negligible and the invocation of an observed rate constant eventuates a compact form of the rate law, which describes the first order growth of the product $[\mathrm{AB}]$ and the first order decay of the reactant $[\mathrm{B}]$.

$$
\frac{d[A B]}{d t}=-\frac{d[B]}{d t}=k_{o b s}[B]
$$

A realistic statement is that the wavelength shift is proportional to the surface amount of AB complex $\Delta \lambda_{t}=\alpha[\mathrm{AB}]_{\mathrm{t}}$ and maximum value of the wavelength shift is proportional to the maximum concentration of the surface complex $\Delta \lambda_{\max }=\alpha[\mathrm{AB}]_{\max }=\alpha[\mathrm{B}]_{0}$. In this way, the integrated form of the pseudo first order rate equation (4) can be rewritten as:

$$
\Delta \lambda_{t}=\Delta \lambda_{\max }\left(1-e^{-k_{o b s} t}\right)
$$

The extraction of the $\mathrm{k}_{\mathrm{a}}$ and $\mathrm{k}_{\mathrm{d}}$ via the $\mathrm{k}_{\mathrm{obs}}$ is a simple linear regression problem, when $\mathrm{k}_{\mathrm{obs}}$ is plotted as a function of analyte concentration; $k_{\mathrm{a}}$ can be obtained from the slope of the curve while the intercept provides the $k_{\mathrm{d}}$. To determine the value of $\mathrm{k}_{\mathrm{obs}}$ we minimized the sum of the square of differences between the measured and predicted (5) wavelength shift using solver add-in function [19]. The typical association and dissociation SPR curves for drug molecule interacting with protein at $283.15 \mathrm{~K}$ are shown in Fig. 4 . The sensorgrams were fitted by using the integrated form of rate equation (5) and the fitted curves were signed with black colour (Fig. 4). The values of $\mathrm{k}_{\mathrm{obs}}$ were plotted as a function of KYNA concentrations at appropriate temperatures (Fig. 5) and the $k_{\mathrm{a}}$ and $k_{\mathrm{d}}$ values were determined according to the following equation: $k_{\mathrm{obs}}=k_{\mathrm{a}}[\mathrm{A}]+k_{\mathrm{d}}$. The slopes of the curves (Fig. 5) belong to the $k_{\mathrm{a}}$, while the intersects give the proper $k_{\mathrm{d}}$ values.

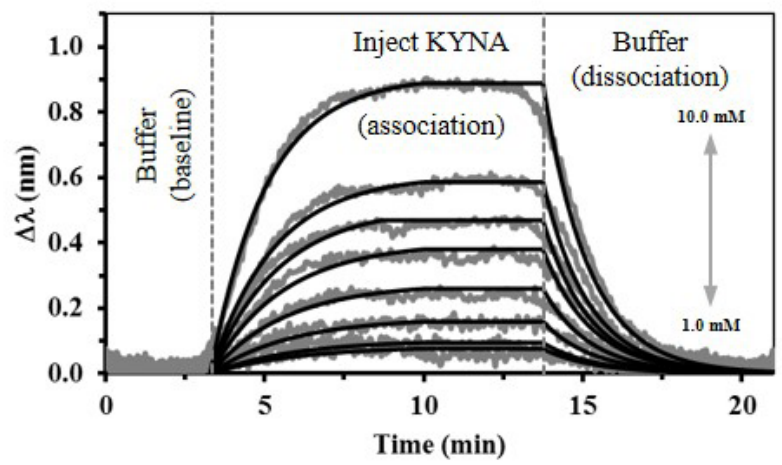

Fig. 4 Representative registered (grey) and the fitted (black) sensorgrams of interaction of KYNA and the immobilized BSA at $283.15 \mathrm{~K}$. The kinetic analyses were achieved via fitting of the experimental data with observed rate constant-based kinetic model (5).
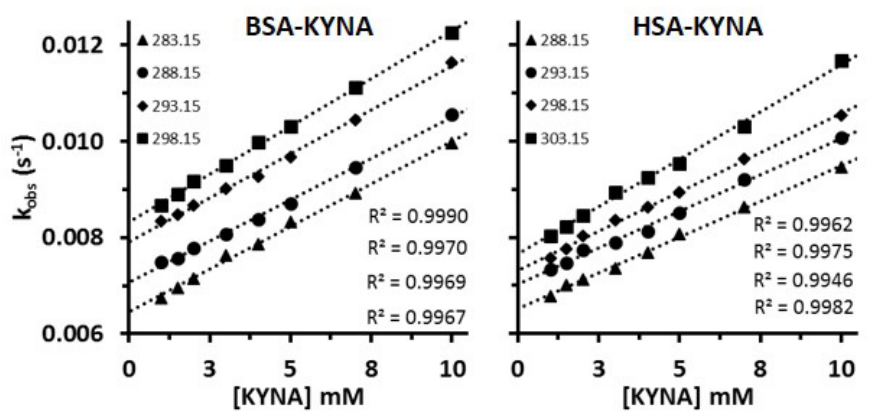

Fig. 5 Values of $\mathrm{k}_{\mathrm{obs}}$ as a function of analyte concentrations in the case of BSA- and HSA-KYNA interaction according to observed rate constant-based kinetic model.

\subsection{Van't Hoff's analysis}

With the purpose of determine the thermodynamics parameters of the investigated binding process initially, the values of $K_{\mathrm{A}}$ were calculated as a ratio of the rate constants $\left(K_{\mathrm{A}}=k_{\mathrm{a}} / k_{\mathrm{d}}\right)$ at each temperatures. At this point the Gibbs free energy values were also calculated according to the following expression:

$$
\Delta G^{0}=\Delta H^{0}-\mathrm{T} \Delta S^{0}=-\mathrm{RT} \ln K_{A}
$$


where $\mathrm{R}$ is the gas constant $\left(8.314 \mathrm{~J} \mathrm{~mol}^{-1} \mathrm{~K}^{-1}\right)$, and $\mathrm{T}$ is the absolute temperature. The values and standard deviations of $\Delta G$ and $\mathrm{K}_{\mathrm{A}}$ of BSA- and HSA-KYNA binding interaction were summarized in Table 1.

Table $1 \mathrm{~K}$ and $\Delta \mathrm{G}$ values of serum albumin - KYNA binding interactions at different temperatures.

\begin{tabular}{|c|c|c|c|c|}
\hline \multirow{2}{*}{$\mathbf{T}(\mathbf{K})$} & \multicolumn{2}{|c|}{ BSA-KYNA } & \multicolumn{2}{|c|}{ HSA-KYNA } \\
\hline & $K_{A}\left(M^{-1}\right)$ & $\Delta \mathbf{G}\left(\mathbf{k J} \mathrm{mol}^{-1}\right)$ & $K_{A}\left(M^{-1}\right)$ & $\Delta \mathrm{G}\left(\mathrm{kJ} \mathrm{mol}^{-1}\right)$ \\
\hline 283.15 & $60 \pm 4$ & $-9.62 \pm 0.04$ & - & - \\
\hline 288.15 & $52 \pm 3$ & $-9.48 \pm 0.04$ & $49 \pm 2$ & $-9.34 \pm 0.03$ \\
\hline 293.15 & $49 \pm 3$ & $-9.50 \pm 0.04$ & $46 \pm 4$ & $-9.36 \pm 0.06$ \\
\hline 298.15 & $51 \pm 2$ & $-9.73 \pm 0.02$ & $48 \pm 3$ & $-9.59 \pm 0.04$ \\
\hline 303.15 & - & - & $55 \pm 4$ & $-10.10 \pm 0.05$ \\
\hline
\end{tabular}

In the next stage of the thermodynamic evaluation, based on the van't Hoff relation, the $\ln \mathrm{K}_{\mathrm{A}}$ values were plotted against the reciprocal temperature $\left(\ln _{\mathrm{A}}\right.$ vs. $\left.1 / \mathrm{T}\right)$ (presented in Fig. 6).

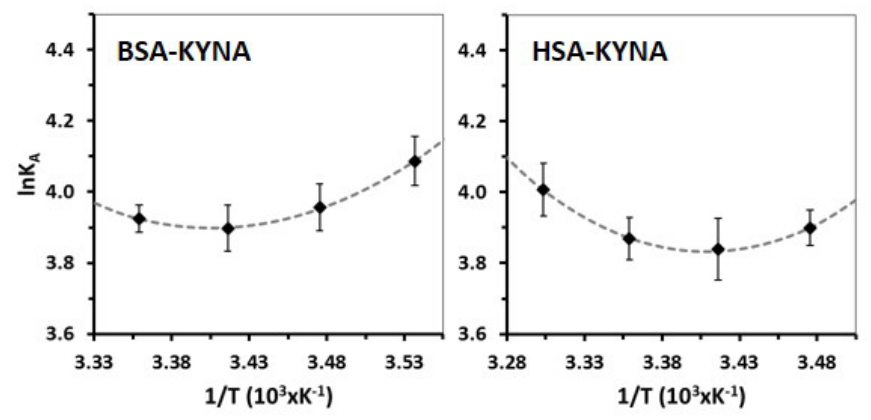

Fig. 6 Natural logarithm of $\mathrm{K}_{\mathrm{A}}$ values and its standard deviations as a function of reciprocal temperature in the case of BSA- and HSA-KYNA interaction.

The dashed grey curves represent the results of the nonlinear van't Hoff analysis.

In several cases, this plot products a straight line, where the slope and the intercept gives the inverse of both enthalpy $\left(-\Delta H^{0} / R\right)$ and the entropy $\left(\Delta S^{0} / R\right)$ changes, correspondingly. In the course of our investigation the shape of above mentioned curve was far from the straight line. As Fig. 6 shows the characteristics of equilibrium constant - temperature data pairs can be described as a convex curve. The thermodynamic parameters for binding interaction were obtained by nonlinear regression analysis with integrated van't Hoff equation (8) and are shown in Table 2.

$$
\ln K_{A}=\frac{-\Delta H^{0}\left(T^{0}\right)}{R T}+\frac{\Delta S^{0}\left(T^{0}\right)}{R}+\frac{\Delta C_{p}}{R}\left[\left(\frac{T-T^{0}}{T}\right)-\ln \frac{T}{T^{0}}\right]
$$

where $\Delta \mathrm{H}^{0}$ and $\Delta \mathrm{S}^{0}$ are the enthalpy and entropy change at the reference temperature, respectively, while $\Delta C_{p}$ is the heat capacity change under standard conditions. This relationship can be used to describe the measured values of the $\mathrm{K}_{\mathrm{a}}$ as a function of reciprocal temperature resulting in the values of thermodynamic parameters as variables of a nonlinear parameter estimation method $[20,21]$. Besides the calculated values of $\Delta H^{0}, \Delta S^{0}$ and $\Delta C_{p}$, the uncertainties of these data are also significant parameters. The small uncertainties denote the finest fit of the experimental data. In order to the determination of standard deviations of the $\Delta H^{0}, \Delta S^{0}$ and $\Delta C_{\mathrm{p}}$ the weighted resampling "jackknife" method was used [22].

Table 2 Thermodynamic parameters of serum albumin - KYNA binding interaction according to the nonlinear van't Hoff analysis.

\begin{tabular}{|c|c|c|c|}
\hline & $\Delta \mathbf{H}^{0}\left(\mathrm{~kJ} \mathrm{~mol}^{-1}\right)$ & $\Delta \mathbf{S}^{0}\left(\mathrm{~J} \mathrm{~mol}^{-1} \mathbf{K}^{-1}\right)$ & $\Delta \mathrm{C}_{\mathrm{p}}\left(\mathrm{kJ} \mathrm{mol}^{-1} \mathrm{~K}^{-1}\right)$ \\
\hline BSA-KYNA & $-1.94 \pm 0.25$ & $25.8 \pm 0.8$ & $-2.17 \pm 0.18$ \\
\hline HSA-KYNA & $-1.87 \pm 0.22$ & $25.5 \pm 0.8$ & $-2.95 \pm 0.09$ \\
\hline
\end{tabular}

Commonly, the interactions between drug molecules and proteins are founded on binding forces such as van der Waals interaction, hydrophobic force, electrostatic interaction and hydrogen bond. Commonly, the interactions between drug molecules and peptides are based on binding forces such as van der Waals interaction, hydrophobic force, electrostatic interaction and hydrogen bond. The thermodynamic parameters like the $\mathrm{H}^{\circ}, \mathrm{S}^{\circ}$ and $\mathrm{G}^{\circ}$ change of binding process are the primal evidences for confirmation of the way of linking [23]. Positive $\Delta H^{0}$ and $\Delta S^{0}$ are frequently taken as evidence for typical hydrophobic interactions, while corresponding negative values arise from van der Waals forces and hydrogen bond formation [24]. Additionally the negative $\Delta H^{\circ}$ and positive $\Delta S^{0}$ are taken evidence that both hydrogen bond and hydrophobic force played an important role in the binding process [25]. Moreover, the sign as well as the absolute value of the heat capacity similarly might be an excellent way to the characterising of the investigated system. Conventionally, large $\Delta C_{\mathrm{p}}$ effects are associated with hydrophobic interactions while the greatness of the effect can be correlated with the changes in solvent accessible surface areas in protein- ligand interaction. A positive $\Delta C_{\mathrm{p}}$ corresponds to the existence of electrostatic interactions, while the negative value denotes a hydrophobic contribution to the binding process and magnitude of this negative $\Delta C_{\mathrm{p}}$ upon aqueous unfolding of the polar interior of the protein [26].

\section{Conclusions}

The principal purpose of the present work was to provide complementary data on the interactions between serum albumins and KYNA by using only SPR experiments and to demonstrate an evaluation method in order to provide valuable thermodynamic parameters. The temperature dependence of kinetics of the interaction between proteins and a drug molecule was detected to show that the values the $\mathrm{k}_{\mathrm{obs}}$ increase in significantly with the temperature and the relationship of $\mathrm{K}_{\mathrm{A}}$ and temperature (accurately reciprocal temperature) can be describable as a convex curve. Values for $\Delta \mathrm{H}^{\circ}, \Delta \mathrm{S}^{\circ}$ and $\Delta \mathrm{Cp}$ of the interaction between the immobilized BSA and KYNA 
were calculated to be $-1.94 \pm 0.25 \mathrm{kJmol}^{-1}, 25.8 \pm 0.8 \mathrm{~J} \mathrm{~mol}^{1} \mathrm{~K}^{-1}$ and $-2.17 \pm 0.18 \mathrm{~kJ} \mathrm{~mol}^{-1} \mathrm{~K}^{-1}$ respectively. Appropriate values of the interaction between immobilized HSA and KYNA were calculated to be $-1.87 \pm 0.22 \mathrm{kJmol}^{-1}, 25.5 \pm 0.8 \mathrm{~J} \mathrm{~mol}^{-1} \mathrm{~K}^{-1}$ and $-2.95 \pm 0.09 \mathrm{~kJ} \mathrm{~mol}^{-1} \mathrm{~K}^{-1}$ respectively.

Negative sign and value of $\Delta \mathrm{G}^{\circ}$ indicated that the formation of serum albumins and KYNA containing surface complexes were thermodynamically favourable while sign and value of $\Delta H^{0}$ and $\Delta S^{0}$ suggested that the binding interactions are predominantly enthalpy driven. Negative $\Delta H^{0}$ and positive $\Delta S^{0}$ are taken evidence that both hydrogen bond and hydrophobic force played a major role in the binding process of KYNA to serum albumins. Moreover the negative $\Delta C_{\mathrm{p}}$ correspondingly denotes a hydrophobic contribution to the binding process. Comparison of the results of present study with the previously published data $[15,16,19]$ gives an evidence of the existing of specific binding affinity and way between KYNA and earliest investigated AMPA receptor peptide fragments.

\section{Acknowledgement}

The research was supported by National Research, Development and Innovation Office-NKFIH through project "Synthesys, structural and thermodynamic characterization of nanohybrid systems at solid-liquid interfaces" K116323 and GINOP-2.3.2-15-2016-00034. The authors thank Zoltán Balogh Molecular Bionics student (University of Szeged, Department of Physical Chemistry and Materials Sciences) for his help in performing SPR measurements.

\section{References}

[1] Mosca, S., Yu, Y., Rebek, J. "Preparative scale and convenient synthesis of a water-soluble, deep cavitand." Nature Protocols. 11, pp. 1371-1387. 2016. https://doi.org/10.1038/nprot.2016.078

[2] Singh, P. K., Nath, S. "Molecular Recognition Controlled Delivery of a Small Molecule from a Nanocarrier to Natural DNA." The Journal of Physical Chemistry B. 117, pp. 10370-10375. 2013. https://doi.org/10.1021/jp402902k

[3] Šípová, H., Ševců, V., Kuchař, M., Ahmad, J. N., Mikulecký, P., Osička, R., Malý, P., Homola, J. "Surface plasmon resonance biosensor based on engineered proteins for direct detection of interferon-gamma in diluted blood plasma." Sensors and Actuators B: Chemical. 174, pp. 306-311. 2012. https://doi.org/10.1016/j.snb.2012.08.024

[4] Š́́pová, H., Piliarik, M., Vala, M., Chadt, K., Adam, P., Bocková, M., Hegnerová, K., Homola, J. "Portable surface plasmon resonance biosensor for detection of nucleic acids." Procedia Engineering. 25. pp. 148 151. 2011. https://doi.org/10.1016/j.proeng.2011.12.037

[5] Homola, J., Yee, S. S., Gauglitz, G. "Surface plasmon resonance sensors: review." Sensors and Actuators B: Chemical. 54. pp. 3-15. 1999. https://doi.org/10.1016/S0925-4005(98)00321-9

[6] Homola, J. "Surface plasmon resonance sensors for detection of chemical and biological species." Chemical Reviews. 108. pp. 462-493. 2008. https://doi.org/10.1021/cr068107d
[7] Boozer, C., Kim, G., Cong, S., Guan, H.-W., Londergan, T "Looking towards label-free biomolecular interaction analysis in a high-throughput format: a review of new surface plasmon resonance technologies." Current Opinion in Biotechnology. 17, pp. 400-405. 2006.

https://doi.org/10.1016/j.copbio.2006.06.012

[8] Patching, S. G. "Surface plasmon resonance spectroscopy for characterisation of membrane protein-ligand interactions and its potential for drug discovery." Biochimica et Biophysica Acta (BBA) - Biomembranes. 1838, pp. 43-55. 2014. https://doi.org/10.1016/j.bbamem.2013.04.028

[9] Š́pová, H., Homola, J. "Surface plasmon resonance sensing of nucleic acids: A review." Analytica Chimica Acta. 773, pp. 9-23. 2013.

https://doi.org/10.1016/j.aca.2012.12.040

[10] Benkő, M., Varga, N., Sebők, D., Bohus, G., Juhász, Á., Dékány, I. "Bovine serum albumin-sodium alkyl sulfates bioconjugates as drug delivery systems." Colloids and Surfaces B: Biointerfaces. 130, pp. 126-132. 2015. https://doi.org/10.1016/j.colsurfb.2015.04.018

[11] Singh, N., Husson, S. M. "Thermodynamic measurements and predictions of the adsorption of short-chain peptides on nanothin polymer films." Biomacromolecules. 6(1), pp. 9-13. 2005.

https://doi.org/10.1021/bm049281j

[12] Csapó, E., Juhász, Á., Varga, N., Sebők, D., Hornok, V., Janovák, L., Dékány, I. "Thermodynamic and kinetic characterization of pH-dependent interactions between bovine serum albumin and ibuprofen in $2 \mathrm{D}$ and 3D systems." Colloids and Surfaces A: Physicochemical and Engineering Aspects. 504, pp. 471-478. 2016.

https://doi.org/10.1016/j.colsurfa.2016.05.090

[13] Erhardt, S., Schwieler, L., Nilsson, L., Linderholm, K., Engberg, G. "The kynurenic acid hypothesis of schizophrenia." Physiology \& Behavior. 92, pp. 203-209. 2007. https://doi.org/10.1016/j.physbeh.2007.05.025

[14] Prescott, C., Weeks, A. M., Staley, K. J., Partin, K. M. "Kynurenic acid has a dual action on AMPA receptor responses." Neuroscience Letters. 402, pp. 108-12. 2006. https://doi.org/10.1016/j.neulet.2006.03.051

[15] Csapó, E., Bogár, F., Juhász, Á., Sebők, D., Szolomájer, J., Tóth, G. K., Majláth, Z., Vécsei, L., Dékány, I. "Determination of binding capacity and adsorption enthalpy between Human Glutamate Receptor (GluR1) peptide fragments and kynurenic acid by surface plasmon resonance experiments. Part 2: Interaction of GluR1270-300 with KYNA." Colloids and Surfaces B: Biointerfaces. 133, pp. 66-72. 2015.

https://doi.org/10.1016/j.colsurfb.2015.04.044

[16] Csapó, E., Majláth, Z., Juhász, Á., Roósz, B., Hetényi, A., Tóth, G. K., Tajti, J., Vécsei, L., Dékány, I. "Determination of binding capacity and adsorption enthalpy between Human Glutamate Receptor (GluR1) peptide fragments and kynurenic acid by surface plasmon resonance experiments." Colloids and Surfaces B: Biointerfaces. 123, pp. 924-929. 2014. https://doi.org/10.1016/j.colsurfb.2014.10.046

[17] Varga, N., Csapó, E., Majláth, Z., Ilisz, I., Krizbai, I. A., Wilhelm, I., Knapp, L., Toldi, J., Vécsei, L., Dékány, I. "Targeting of the kynurenic acid across the blood-brain barrier by core-shell nanoparticles." European Journal of Pharmaceutical Sciences. 86, pp. 67-74. 2016. https://doi.org/10.1016/j.ejps.2016.02.012

[18] Kiselev, M. A., Gryzunov, I. A., Dobretsov, G. E., Komarova, M. N. "[Size of a human serum albumin molecule in solution]." Biofizika. 46, pp. 4237. 2001. (in Russian) http://www.ncbi.nlm.nih.gov/pubmed/11449540

[19] Juhász, Á., Csapó, E., Ungor, D., Tóth, G. K., Vécsei, L., Dékány, I. "Kinetic and Thermodynamic Evaluation of Kynurenic Acid Binding to GluR1 270-300 Polypeptide by Surface Plasmon Resonance Experiments." The Journal of Physical Chemistry B. 120, pp. 7844-7850. 2016. https://doi.org/10.1021/acs.jpcb.6b05682 
[20] Li, X., Song, S., Shuai, Q., Pei, Y., Aastrup, T., Pei, Y., Pei, Z. "Real-time and label-free analysis of binding thermodynamics of carbohydrate-protein interactions on unfixed cancer cell surfaces using a QCM biosensor." Scientific Reports. 5, 14066. 2015. https://doi.org/10.1038/srep14066

[21] Harris, D. C. "Nonlinear Least-Squares Curve Fitting with Microsoft Excel Solver." Journal of Chemical Education. 75, p. 119. 1998. https://doi.org/10.1021/ed075p119

[22] Caceci, M. S. "Estimating error limits in parametric curve fitting." Analytical Chemistry. 61, pp. 2324-2327. 1989.

https://doi.org/10.1021/ac00195a023

[23] Ross, P. D., Subramanian, S. "Thermodynamics of protein association reactions: forces contributing to stability." Biochemistry. 20, pp. 30963102. 1981. https://doi.org/10.1021/bi00514a017

[24] Tian, Z. Y., Song, L. N., Zhao, Y., Zang, F. L., Zhao, Z. H., Chen, N. H., $\mathrm{Xu}, \mathrm{X}$. J., Wang, C. J. "Spectroscopic Study on the Interaction between Naphthalimide-Polyamine Conjugates and Bovine Serum Albumin (BSA)." Molecules. 20, pp. 16491-16523. 2015.

https://doi.org/10.3390/molecules200916491
[25] Cui, F. L., Hui, G. Q., Huo, R. N., Qu, G. R. "The binding characteristics of the interaction between 3-(2-cyanoethyl) cytosine and human serum albumin." Molecular Biology Reports. 39, pp. 9885-9891. 2012. https://doi.org/10.1007/s11033-012-1855-x

[26] Cooper, A., Johnson, C. M., Lakey, J. H., Nöllmann, M. "Heat does not come in different colours: entropy-enthalpy compensation, free energy windows, quantum confinement, pressure perturbation calorimetry, solvation and the multiple causes of heat capacity effects in biomolecular interactions." Biophysical Chemistry. 93, pp. 215-230. 2001. https://doi.org/10.1016/S0301-4622(01)00222-8 